\title{
Adverse Drug Reactions with HER2-Positive Breast Cancer Treatment: An Analysis from the Italian Pharmacovigilance Database
}

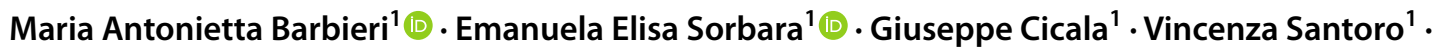 \\ Paola Maria Cutroneo ${ }^{2} \cdot$ Tindara Franchina $^{3} \cdot$ Edoardo Spina $^{1}$ (1)
}

Accepted: 23 August 2021 / Published online: 15 September 2021

(c) The Author(s) 2021

\begin{abstract}
Background Anti-HER2 therapy has evolved in the last years and an important role in this transformation was that of monoclonal antibodies and tyrosine kinase inhibitors. Considering their extended use in clinical practice, some toxicity problems have been highlighted around these drugs.

Objective To analyze the onset of adverse drug reactions (ADRs) related to the use of HER2-positive breast cancer treatments through a spontaneous reporting system (SRS) database.

Methods All ADR reports having as suspected drug trastuzumab, pertuzumab, lapatinib, or trastuzumab emtansine (TDM-1), recorded into the Report Reazioni Avverse dei Medicinali (RAM) system database for national data and into the Italian SRS database for Sicilian data and collected from 2006 to 2020 have been evaluated. A descriptive analysis of basal demographic and drug-related characteristics was performed. A case-by-case methodology was conducted paying particular attention to the serious ADR reports collected in Sicily, focusing on type of seriousness, age, sex, concomitant drugs, comorbidities, time to onset (TTO), and time to resolution (TTR).

Results Of the 3609 Italian reports, $65.6 \%$ were related to trastuzumab $(n=2367)$, followed by pertuzumab, TDM-1, and lapatinib. Almost all reports occurred in female patients (94.3\%) and were most frequent in the age group 18-65 years (69.6\%). A higher number of cases were related to general disorders and administration site conditions $(n=1079 ; 29.9 \%)$, gastrointestinal disorders $(n=1037 ; 28.7 \%)$, skin disorders $(n=821 ; 22.7 \%)$, and blood disorders $(n=599 ; 16.6 \%)$. Cases involving trastuzumab and pertuzumab mainly reported general disorders $(n=788 ; 33.3 \%$ and $n=194 ; 32.1 \%$, respectively) while more than half of the reports associated with lapatinib were related to gastrointestinal $(n=184 ; 59.7 \%)$ and skin diseases $(n=146 ; 47.4 \%)$. Regarding TDM-1, 40\% of reports had at least one ADR belonging to blood and lymphatic system disorders. The case-by-case assessment of Sicilian ADR reports showed that 40 cases were serious (33.3\%), with a median TTO of 37 (6-97) days. Serious ADR reports mainly involved the onset of thrombocytopenia $(n=8 ; 20.0 \%)$, diarrhea $(n=$ $6 ; 15.0 \%$ ), asthenia and cardiac failure (both with $n=5 ; 12.5 \%$ ), vomiting, hypersensitivity, and ejection fraction decreased (all with $n=4 ; 10.0 \%$ ) and stomatitis $(n=3: 7.5 \%)$.

Conclusion This study is fundamentally consistent with results from the literature. Given the serious clinical condition of breast cancer and taking into account the importance of preventing some clinically relevant ADRs related to the use of antiHER2 therapy, further analyses are essential to better describe the safety profile of these target therapies.
\end{abstract}

\section{Introduction}

Edoardo Spina

espina@unime.it

1 Department of Clinical and Experimental Medicine, University of Messina, Messina, Italy

2 Sicilian Regional Pharmacovigilance Centre, University Hospital of Messina, Messina, Italy

3 Department of Adult and Developmental Human Pathology "Gaetano Barresi", University of Messina, Messina, Italy

Breast cancer was the most commonly diagnosed type of cancer worldwide in 2020, accounting for approximately 2.3 million new cases [1]. Moreover, it is also considered one of the main causes of cancer death in women. In recent years, the incidence of breast tumors increased considerably due to screening and surveillance programs and early identification, which resulted in a greater number of new diagnoses especially at early-stage cancer $[2,3]$. In 6-7\% of cases the neoplasm occurs in a metastatic form. About 


\section{Key Points}

The importance of the Spontaneous Reporting System (SRS) database for the identification of adverse drug reactions (ADRs) related to the use of human epidermal growth factor receptor type 2 (HER2)-positive breast cancer treatments is shown in the present study.

A higher frequency of cardiac disorders, palmar-plantar erythrodysesthesia (PPE) syndrome, thrombocytopenia, and infusion-related reactions was noticed for anti-HER2 therapy.

The collaboration between oncologists and pharmacologists plays an essential role in early identification of ADRs, informing patients and improving their awareness to report any new symptoms or worsening of a preexisting condition as soon as possible during anti-HER2 therapy.

$12-15 \%$ of cases of early breast cancer (EBC) and 20-30\% of cases of metastatic breast cancer (MBC) are characterized by protein overexpression or gene amplification of the human epidermal growth factor receptor type 2 (HER2) [4, 5]. HER 2 is a member of the HER family with a tyrosine kinase activity. Homo- or heterodimerization leads to the autophosphorylation of tyrosine residues into the cytoplasmic domain with the subsequent activation of different signaling pathways that stimulate cell proliferation, migration, invasion, angiogenesis, and survival $[6,7]$. These five mechanisms belong to the "Hallmarks of cancer" and are crucial for tumor growth [8].

The treatment of HER2-positive breast cancer has radically changed over the last 20 years. Before the introduction into the market of the HER2-targeted monoclonal antibodies, HER2-positive breast cancer was characterized by lower survival and high recurrence rates [5]. Today, the evolution of standard of care involves (neo) adjuvant and metastatic therapy, including the associated use of novel therapies $[9$, 10]. The first therapy approved for HER2-positive MBC included the use of trastuzumab or pertuzumab in association with chemotherapeutic agents such as taxanes and vinca alkaloids. In a recent clinical trial, it has been shown that the use of monoclonal antibodies with chemotherapy achieves a better response in terms of survival than chemotherapy alone [11]. These drugs have also been approved over time for the treatment of EBC. Moreover, in 2013 the drug-antibody conjugate trastuzumab emtansine (TDM-1) was approved for the adjuvant treatment of adult patients with HER2-positive EBC who have residual invasive disease, in the breast and/ or lymph nodes, after neoadjuvant taxane-based and HER2targeted therapy and for unresectable locally advanced breast cancer or MBC who previously received trastuzumab and a taxane, separately or in combination [12]. In recent years, two tyrosine kinase inhibitors, lapatinib and neratinib, have been approved for breast cancer treatment: lapatinib for progressive or advanced breast cancer in combination with capecitabine, trastuzumab or aromatase inhibitors, and neratinib for HER2-positive EBC [13, 14].

Some toxicity problems have been highlighted in clinical trials and post-marketing studies. Cardiac toxicity is the main side effect of anti-HER2 monoclonal antibodies with an incidence ranging from $0.7 \%$ to $12.0 \%[15,16]$. Allergic reactions may also occur in approximately $40 \%$ of patients during or immediately after the infusion, characterized by a real cytokine release syndrome (fever, chills, hypotension, dyspnea, skin rash) $[11,17]$. The monoclonal antibody pertuzumab prevents heterodimerization of the EGFR receptor and $\mathrm{ErB} 2$, and can lead to the onset of diarrhea (in from $45 \%$ to $72 \%$ of cases) [18-21]. Anti-HER2 drugs, particularly trastuzumab, TDM-1, and lapatinib, have also been associated with the onset of interstitial lung disease with an overall incidence of $2.4 \%$ that reached $21.4 \%$ with trastuzumab [22]. Treatment with tyrosine kinase inhibitors can lead to hepatotoxicity, diarrhea, neutropenia, leukopenia, and severe skin reactions such as palmar-plantar erythrodysesthesia syndrome (PPE) (more than 25\%) [23-25].

Given the clinical relevance of the adverse effects that have appeared in clinical trials and considering the recent market introduction of new anti-HER2 therapy and its extensive use in clinical practice, it may be useful to identify new and unexpected adverse drug reactions (ADRs) that may arise during the use of these drugs in the real world. In view of the above findings, the aim of this study was to evaluate ADRs related to HER2-positive breast cancer treatment and reported into the Italian Spontaneous Reporting System (SRS) database focusing on the Sicilian region.

\section{Methods}

\subsection{Data Source}

The Italian SRS database is managed by the Italian Medicines Agency (AIFA), which works closely with Pharmacovigilance Regional Centers (PRCs) for every possible safety signal detection. The SRS database consists of all ADR reports sent by healthcare professionals and citizens or by the Marketing Authorisation Holders (MAHs) at national level. Each ADR report collected into the Italian SRS database includes detailed information on patient (e.g., name/ surname initials, age, gender), description of ADRs (e.g., time to onset (TTO) and time to recovery (TTR), seriousness, outcome, dechallenge, rechallenge), suspected and concomitant drugs (e.g., dosage, frequency and route of 
administration, therapeutic indication), clinical history, and comorbidities. Drug classification is carried out using the Anatomical Therapeutic Chemical (ATC) classification (WHOCC), while suspected ADRs are categorized according to the Medical Dictionary for Regulatory Activities $\left(\right.$ MedDRA ${ }^{\circledR}$ ).

Each single PRC, such as the Sicilian Pharmacovigilance Center, operates through a National Pharmacovigilance network to support the pharmacovigilance system with full access to specific regional data collected in Italian SRS. Regarding overall national data, the AIFA has created an online open-access system (Report Reazioni Avverse dei Medicinali, RAM) that provides an overview of all Italian ADR reports collected into the Italian SRS database and allows access to aggregated data relating to Italian reports recorded since 2002, organised by year of entry in the Italian SRS database. Only the following information are available from the RAM system: information about the total number of reports recorded broken down by year; the number and percentage of reports by seriousness; the number and percentage of reports by sex and age group of subjects who have experienced the ADR(s); the number and percentage of aggregated ADRs classified by System Organ Class (SOC) and Preferred Term (PT).

In accordance with the seriousness, ADRs can be divided into serious and not serious. An ADR is classified as serious when it proves to be life-threatening or fatal, requires inpatient hospitalization or prolongation of existing hospitalization, results in persistent or significant disability/incapacity, is a congenital anomaly/birth defect, or is another important medical event (IME) [26].

\subsection{Case Definition and Selection Criteria}

A retrospective observational study was conducted between January 2006 and December 2020 to evaluate the safety of drugs approved for HER2-positive breast cancer in a realworld setting. First of all, we included all ADR reports from the RAM system for national data in aggregated form and from the SRS database for Sicilian data in detailed form. The selection of data concerned all reports having at least one of the following drugs registered as suspected: trastuzumab (L01XC03), trastuzumab emtansine (L01XC14), pertuzumab (L01XC13), and lapatinib (L01EH01). Trastuzumab deruxtecan and neratinib were not considered due to their recent authorization onto the Italian market. Literature and duplicate cases were excluded from analysis of Sicilian data, as well as reports with trastuzumab having as indication metastatic gastric cancer.

In detail, the analysis was performed at the case level and reports containing more than one ADR were counted only once.

\subsection{Data Analysis}

A descriptive analysis of regional data and aggregate national reports of study drugs was conducted to evaluate the basal demographic and drug-related characteristics. Specifically, we performed analyses by year, sex, age, seriousness, and outcome. Furthermore, ADRs were analyzed taking into account the MedDRA ${ }^{\circledR}$ System Organ Class (SOC) and Preferred Term (PT) grouping the same ADR reports into the equivalent SOC and clustering the synonymous PTs of the same clinical condition under one term (see Online Supplementary Material S1).

We also performed a case-by-case assessment paying particular attention to the serious ADR reports collected in the Sicilian region focusing on type of seriousness, age, sex, concomitant drugs, comorbidities, TTO, and TTR. TTO and TTR were expressed in days and were calculated considering the time elapsed between the start of the drug use and the onset of the ADR and the time elapsed between the onset and the resolution of ADR where possible, respectively. Moreover, the Naranjo algorithm was used to evaluate the potential causal relationship between the serious clinical event and the suspected drug. Each ADR can be classified as: high probable (score $\geq 9$ ), probable (scores 5-8), possible (scores 1-4), or doubtful (score $\leq 0$ ) [27]. Absolute and relative frequencies were evaluated for categorical variables, while medians with interquartile intervals (Q1-Q3) were used to evaluate continuous variables.

ADRs were defined as expected for each drug if reported into the Summary of Product Characteristics (SPCs) available at the time of the analysis by the European Medicines Agency (EMA) website [28].

\section{Results}

This study included all ADRs collected between 1 January 2006 and 31 December 2020. A total of 3609 reports, having as suspected drugs at least one of anti-HER2 medications, were collected in the SRS and listed in the RAM system database. Specifically, $65.6 \%$ were related to the active substance trastuzumab $(n=2367)$, followed by pertuzumab ( $n$ $=604)$, TDM-1 $(n=330)$, and lapatinib $(n=308)$. With regard to trastuzumab-related reports, $1986(83.9 \%)$ reported the trade name of the medicinal product. More than $88 \%$ of reports were associated with the originator trastuzumab Herceptin ${ }^{\circledR}(n=1753)$ and only 233 reports $(11.7 \%)$ concerned trastuzumab biosimilars (in detail: Kanjinty ${ }^{\circledR}, n=83$, 4.2\%; Herzuma ${ }^{\circledR}, n=77,3.9 \%$; Ontruzant ${ }^{\circledR}, n=68,3.4 \%$; Ogivri $^{\circledR}, n=4,0.2 \%$; Trazimera $\left.^{\circledR}, n=1 ; 0.1 \%\right)$. The reporting of anti-HER2 drug-related ADRs gradually increased over the years until 2018, with an important peak in 2019; trastuzumab showed a similar trend in the considered reports 
over the years and a major increase was highlighted for pertuzumab since 2015 (Fig. 1).

Demographic characteristics including seriousness, sex, and age group are described in Table 1. Regarding the seriousness, ADRs were mainly not serious ( $n=2490 ; 69.0 \%)$. Almost all the reports occurred in female patients (94.3\%) and were more frequently in the age group 18-65 years (69.6\%) (Table 1).

The analysis of ADRs underlined a higher number of cases related to the SOC "general disorders and administration site conditions" ( $n=1079 ; 29.9 \%)$ mainly focusing on asthenia and "gastrointestinal disorders" $(n=1037 ; 28.7 \%)$ mostly related to diarrhea. These SOCs were followed by "skin and subcutaneous tissue disorders" $(n=821 ; 22.7 \%)$ such as rash and "blood and lymphatic system disorders" ( $n$ $=599 ; 16.6 \%$ ) including neutropenia and thrombocytopenia. Trastuzumab and pertuzumab cases mostly reported general disorders and administration site conditions $(n=788$; $33.3 \%$ and $n=194 ; 32.1 \%$, respectively) while about half of reports associated with lapatinib involved gastrointestinal disorders $(n=184 ; 59.7 \%)$ and skin diseases $(n=146$; $47.4 \%)$. Regarding TDM-1, $40 \%$ of reports had at least one ADR belonging to the SOC blood and lymphatic system disorders (Table 2). Trastuzumab as the originator was mostly reported for the onset of diarrhea $(n=127 ; 7.2 \%)$ neutropenia $(n=113 ; 6.5 \%)$, asthenia $(n=103 ; 5.9 \%)$, pyrexia $(n=$ 94; 5.4\%), and decreased ejection fraction $(n=90 ; 5.1 \%)$. Trastuzumab biosimilars were mainly reported for the onset of chills $(n=54 ; 23.2 \%)$, pyrexia $(n=28 ; 12.0 \%)$, diarrhea $(n=26 ; 11.2 \%)$, and asthenia $(n=25 ; 10.7 \%)$.

The Italian SRS database contains 28,383 reports related to Sicily and collected from 2001 to 2020 ; of them, 126 had as suspected drug at least one anti-HER2 therapy $(0.4 \%)$. In accordance with the exclusion criteria, 120 reports were considered for this analysis, of which only 11 cases had pertuzumab and trastuzumab reported concomitantly as suspected (9.2\%) (Fig. 2). Trastuzumab was the most reported active substance $(n=59 ; 49.2 \%)$ followed by lapatinib ( $n$ $=27 ; 22.5 \%)$, TDM-1 $(n=18 ; 15.0 \%)$, and pertuzumab $(n=5 ; 4.2 \%)$. Considering trastuzumab, only nine ADR reports were related to biosimilar formulations (15.3\% of the total number of trastuzumab-related reports) and 14 cases reported trastuzumab administered subcutaneously as the suspected drug $23.7 \%$ of the total number of trastuzumabrelated reports). An association of two or more antineoplastic agents was reported in 27 reports $(22.5 \%)$ and mostly included lapatinib plus capecitabine $(n=9 ; 7.5 \%)$ and trastuzumab plus pertuzumab plus docetaxel $(n=6 ; 5.0 \%)$. The trend almost increased over the years with a peak in 2015 $(n=34 ; 28.3 \%)$ and subsequently decreased in later years. Almost all the Sicilian reports involved females $(n=118$; 98.3\%) with a median age of 54 (49-64.3) years. Regarding the characteristics, ADR reports were mostly not serious ( $n$ $=75 ; 62.5 \%)$, fully recovered $(n=46 ; 38.3 \%)$, and reported by a physician $(n=79 ; 65.8 \%)$ (Table 3$)$.

ADR classifications of general and administration site disorders and gastrointestinal diseases were the most
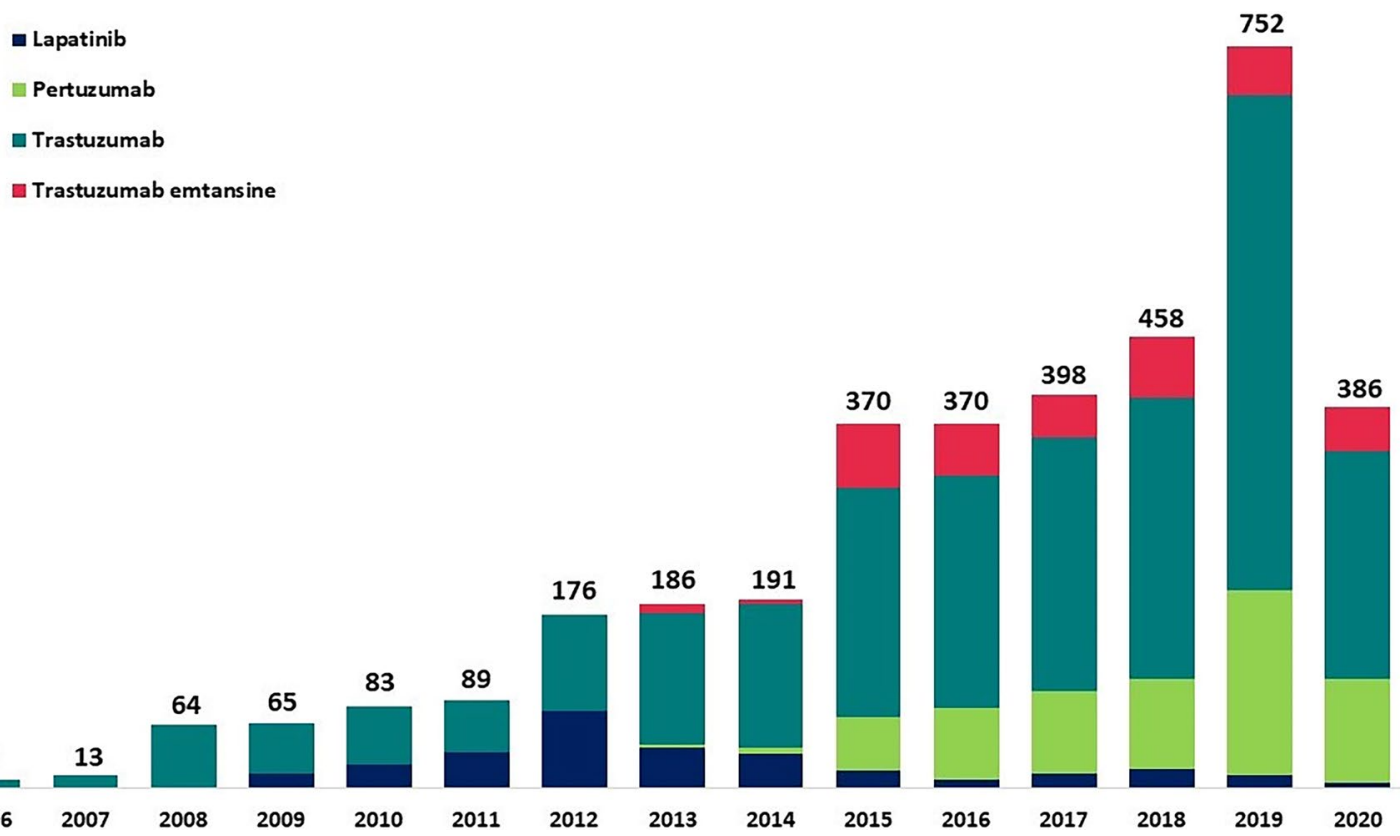

Fig. 1 Italian trend of anti-HER2 therapy-related adverse drug reaction (ADR) reports collected into the RAM (Report Reazioni Avverse dei Medicinali) system over the years 2006-2020 
Table 1 Descriptions of Italian anti-HER2 therapy-related adverse drug reaction (ADR) reports collected into the RAM (Report Reazioni Avverse dei Medicinali) system from January 2006 to December 2020.

\begin{tabular}{|c|c|c|c|c|c|}
\hline Characteristic, $n(\%)$ & Lapatinib $(n=308)$ & Pertuzumab $(n=604)$ & Trastuzumab $(n=2367)$ & TDM-1 $(n=330)$ & Total $(n=3609)$ \\
\hline \multicolumn{6}{|l|}{ Seriousness } \\
\hline Serious & $60(19.5)$ & $194(32.1)$ & $712(30.1)$ & $112(33.9)$ & 1078 (29.9) \\
\hline Not serious & $245(79.5)$ & $404(66.9)$ & $1,632(68.9)$ & $209(63.3)$ & $2490(69.0)$ \\
\hline Not available & $3(1.0)$ & $6(1.0)$ & $23(1.0)$ & $9(2.7)$ & $41(1.1)$ \\
\hline \multicolumn{6}{|l|}{ Gender } \\
\hline Male & $1(0.3)$ & $8(1.3)$ & $167(7.1)$ & $3(0.9)$ & $179(5.0)$ \\
\hline Female & $305(99.0)$ & $591(97.8)$ & $2189(92.5)$ & $319(96.7)$ & $3404(94.3)$ \\
\hline Not available & $2(0.6)$ & $5(0.8)$ & $10(0.4)$ & $8(2.4)$ & $25(0.7)$ \\
\hline \multicolumn{6}{|l|}{ Age groups, years } \\
\hline $18-65$ & $224(72.7)$ & 439 (72.7) & $1637(69.2)$ & $210(63.6)$ & $2510(69.6)$ \\
\hline$\geq 66$ & $79(25.6)$ & $143(23.7)$ & $655(27.7)$ & $87(26.4)$ & $964(26.7)$ \\
\hline Not available & $5(1.6)$ & $22(3.6)$ & $75(3.2)$ & $33(10.0)$ & $135(3.7)$ \\
\hline
\end{tabular}

TDM-1 trastuzumab emtansine

reported ( $n=36 ; 30.0 \%$ and $28 ; 23.3 \%$, respectively) followed by cardiac $(n=18 ; 15.0 \%)$, skin $(n=17 ; 14.2 \%)$, and blood disorders $(n=14 ; 11.7 \%)$. Trastuzumab, including biosimilars, was mostly related to general conditions, in particular chills and cardiac disorders involving cardiac failure, while lapatinib was mostly associated with gastrointestinal diseases such as diarrhea and skin disorders including PPE syndrome; half of TDM-1-related ADRs reported blood disorders involving thrombocytopenia; in addition, the five cases of pertuzumab had at least one vascular disorder (Table 4). With regard to trastuzumab administered subcutaneously, seven ADRs concerned cardiac disorders, including heart disease and decreased ejection fraction, while four cases were associated with skin and allergic reactions.

The case-by-case assessment of serious Sicilian ADR reports is shown in Table 5. Of the 120 collected reports, 40 were serious $(33.3 \%)$ and mostly concerned an IME ( $n$ $=18 ; 45.0 \%)$ with a median TTO of 37 (6-97) days. The totality involved females with a median age of 59 (50-66) years. Regarding the outcome, ADR reports were mostly improved or fully recovered $(n=14 ; 35.0 \%$ and $n=12$; $30.0 \%$, respectively), with a median TTR of $5(0-33)$ days. The causality assessment showed that 21 ADRs were possible (52.5\%), while 19 were probable (47.5\%). Trastuzumab was the most reported suspected drug $(n=14 ; 35.0 \%)$ followed by TDM-1 $(n=6 ; 15.0 \%)$ and by the combinations of lapatinib + capecitabine and trastuzumab + pertuzumab (both with $n=4 ; 10.0 \%$ ). Concomitant drugs mostly were paclitaxel and docetaxel $(n=5 ; 12.5 \%$ and $n=2 ; 5.0 \%$, respectively). Serious ADR reports mainly involved blood, gastrointestinal, general, and cardiac disorders, especially with the onset of thrombocytopenia $(n=8 ; 20.0 \%)$, diarrhea $(n=6 ; 15.0 \%)$, asthenia and cardiac failure (both with $n=5 ; 12.5 \%)$, vomiting, hypersensitivity and decreased ejection fraction (all with $n=4 ; 10.0 \%$ ), and stomatitis ( $n$ $=3: 7.5 \%$ ) (Table 5). Trastuzumab-related cardiac events had a median TTO of 103 (70.3-259.8) days. Looking at each single life-threatening event, ADR reports were mostly related to pertuzumab and trastuzumab. Specifically, cardiac failure and infusion-related reactions with hypersensitivity were more frequent.

\section{Discussion}

This study aimed to identify anti-HER2 therapy-related ADRs collected in the RAM system database for national data and in the SRS database for Sicilian data. Breast cancer in men is a rare disease, particularly in the metastatic setting, thus a higher prevalence of ADR reports has been recorded in women in accordance with other studies [29, 30]. Literature data confirmed patients' demographic characteristics, especially median age [31, 32], sex differences [33], and seriousness $[34,35]$. No substantial differences were noted between national and Sicilian data. The $0.4 \%$ of ADRs collected into the Italian SRS database and coming from Sicily were related to anti-HER2 therapy. Trastuzumab shows the highest number of ADR reports, and this is presumably due to being on the market for the longest time, to entry into the Registries and web-based therapeutic plans of medicines subjected to AIFA monitoring from January 2011, and to the introduction of biosimilars from 2017 [36]. Moreover, pertuzumab-related ADRs increased in 2015 despite its authorization in March 2013; this could be explained by the greatest increase in consumption registered in 2015 compared to 2014, but also because pertuzumab was added into the AIFA registries from July 2014 [37]. 
Table 2 Descriptions of adverse drug reactions associated with HER2-positive breast cancer treatment and reported into the RAM (Report Reazioni Avverse dei Medicinali) system

\begin{tabular}{|c|c|c|c|c|c|}
\hline Adverse drug reaction, $n(\%)^{\mathrm{a}}$ & Lapatinib $(n=308)$ & Pertuzumab $(n=604)$ & $\begin{array}{l}\text { Trastuzumab } \\
(n=2367)\end{array}$ & TDM-1 $(n=330)$ & Total $(n=3609)$ \\
\hline $\begin{array}{l}\text { General disorders and administration site } \\
\text { conditions }\end{array}$ & $50(16.2)$ & $194(32.1)$ & $788(33.3)$ & $82(2.8)$ & $1079(29.9)$ \\
\hline Asthenia & $24(7.8)$ & $56(9.3)$ & $173(7.3)$ & $23(7.0)$ & $276(76)$ \\
\hline Pyrexia & $5(1.6)$ & $28(4.6)$ & $131(5.5)$ & $15(4.5)$ & $179(5.0)$ \\
\hline Chills & & $14(2.3)$ & $154(6.5)$ & $5(1.5)$ & $173(4.8)$ \\
\hline Hyperpyrexia & $1(0.3)$ & $6(1.0)$ & $38(1.6)$ & $3(0.9)$ & $48(1.3)$ \\
\hline Gastrointestinal disorders & $184(59.7)$ & $177(29.3)$ & $627(26.5)$ & $49(14.8)$ & $1037(28.7)$ \\
\hline Diarrhea & $111(36.0)$ & $79(13.1)$ & $175(7.4)$ & $8(2.4)$ & $373(10.3)$ \\
\hline Nausea & $16(5.2)$ & $23(3.8)$ & $114(4.8)$ & $8(2.4)$ & $161(4.5)$ \\
\hline Vomiting & $19(6.2)$ & $15(2.5)$ & $88(3.7)$ & $5(1.5)$ & $127(3.5)$ \\
\hline Abdominal pain & $10(3.2)$ & $15(2.5)$ & $70(3.0)$ & $5(1.5)$ & $100(2.8)$ \\
\hline Skin and subcutaneous tissue disorders & $146(47.4)$ & $172(28.5)$ & 467 (19.7) & $36(10.9)$ & $821(22.7)$ \\
\hline Rash & $63(20.5)$ & $52(8.6)$ & $152(6.4)$ & $12(3.6)$ & $279(7.7)$ \\
\hline Pruritus & $6(1.9)$ & $47(7.8)$ & $93(3.9)$ & $7(2.1)$ & $153(4.2)$ \\
\hline Alopecia & & $15(2.5)$ & $38(1.6)$ & $2(0.6)$ & $55(1.5)$ \\
\hline Palmar-plantar erythrodysesthesia syndrome & $26(8.4)$ & $1(0.2)$ & $4(0.2)$ & $1(0.3)$ & $32(0.9)$ \\
\hline Blood and lymphatic system disorders & $11(3.6)$ & $89(14.7)$ & $367(15.5)$ & $132(40.0)$ & $599(16.6)$ \\
\hline Neutropenia & $4(1.3)$ & $32(5.3)$ & $160(6.8)$ & $21(6.4)$ & $217(6.0)$ \\
\hline Thrombocytopenia & $2(0.6)$ & $9(1.5)$ & $62(2.6)$ & $88(26.7)$ & $161(4.5)$ \\
\hline Anemia & $4(1.3)$ & $28(4.6)$ & $88(3.7)$ & $11(3.3)$ & $131(3.6)$ \\
\hline Leukopenia & & $11(1.8)$ & $41(1.7)$ & $5(1.5)$ & $57(1.6)$ \\
\hline Nervous system disorders & $13(4.2)$ & $82(13.6)$ & $367(15.5)$ & $31(9.4)$ & 493 (13.7) \\
\hline Paresthesia & $3(1.0)$ & $28(4.6)$ & $97(4.1)$ & $8(2.4)$ & $136(3.8)$ \\
\hline Tremor & & $10(1.7)$ & $96(4.1)$ & $1(0.3)$ & $107(3.0)$ \\
\hline Headache & $1(0.3)$ & $10(1.7)$ & $44(1.9)$ & $5(1.5)$ & $60(1.7)$ \\
\hline Dysgeusia & & $8(1.3)$ & $33(1.4)$ & $1(0.3)$ & $42(1.2)$ \\
\hline $\begin{array}{l}\text { Respiratory, thoracic, and mediastinal disor- } \\
\text { ders }\end{array}$ & $10(3.2)$ & $94(15.6)$ & $314(13.3)$ & $36(10.9)$ & 454 (12.6) \\
\hline Dyspnea & $4(1.3)$ & $31(5.1)$ & $117(4.9)$ & $3(0.9)$ & $155(4.3)$ \\
\hline Epistaxis & $3(1.0)$ & $11(1.8)$ & $36(1.5)$ & $14(4.2)$ & $64(1.8)$ \\
\hline Cough & $1(0.3)$ & $11(1.8)$ & $28(1.2)$ & $7(2.1)$ & $47(1.3)$ \\
\hline Bronchospasm & & $7(1.2)$ & $21(0.9)$ & & $28(0.8)$ \\
\hline Cardiac disorders & $3(1.0)$ & $45(7.5)$ & $254(10.7)$ & $10(3.0)$ & $312(8.6)$ \\
\hline Cardiac failure & & $6(1.0)$ & $64(2.7)$ & & $70(1.9)$ \\
\hline Tachycardia & $1(0.3)$ & $12(2.0)$ & $43(1.8)$ & $2(0.6)$ & $58(1.6)$ \\
\hline Cardiotoxicity & & $2(0.3)$ & $22(0.9)$ & $4(1.2)$ & $28(0.8)$ \\
\hline Palpitations & & $5(0.8)$ & $16(0.7)$ & $1(0.3)$ & $22(0.6)$ \\
\hline Investigations & $24(7.8)$ & $49(8.1)$ & $194(8.2)$ & $35(10.6)$ & $253(7.0)$ \\
\hline Ejection fraction decreased & $4(1.3)$ & $23(3.8)$ & $107(4.5)$ & $9(2.7)$ & $143(4.0)$ \\
\hline Oxygen saturation decreased & & $7(1.2)$ & $12(0.5)$ & & $19(0.5)$ \\
\hline Alanine aminotransferase increased & & $2(0.3)$ & $2(0.1)$ & $3(0.9)$ & $7(0.2)$ \\
\hline Aspartate aminotransferase increased & $1(0.3)$ & $1(0.2)$ & $1(0.0)$ & $4(1.2)$ & $7(0.2)$ \\
\hline $\begin{array}{l}\text { Musculoskeletal and connective tissue disor- } \\
\text { ders }\end{array}$ & $3(1.0)$ & $48(7.9)$ & $201(8.5)$ & $19(5.8)$ & $271(7.5)$ \\
\hline Arthralgia & $2(0.6)$ & $8(1.3)$ & $52(2.2)$ & $3(0.9)$ & $65(1.8)$ \\
\hline Myalgia & & $7(1.2)$ & $38(1.6)$ & $3(0.9)$ & $48(1.3)$ \\
\hline Back pain & & $9(1.5)$ & $25(1.1)$ & $2(0.6)$ & $36(1.0)$ \\
\hline Pain in extremity & & $4(0.7)$ & $27(1.1)$ & $2(0.6)$ & $33(0.9)$ \\
\hline
\end{tabular}


Table 2 (continued)

\begin{tabular}{|c|c|c|c|c|c|}
\hline Adverse drug reaction, $n(\%)^{\mathrm{a}}$ & Lapatinib $(n=308)$ & Pertuzumab $(n=604)$ & $\begin{array}{l}\text { Trastuzumab } \\
(n=2367)\end{array}$ & TDM-1 $(n=330)$ & Total $(n=3609)$ \\
\hline Vascular disorders & $9(2.9)$ & $49(8.1)$ & $152(6.4)$ & $7(2.1)$ & $217(6.0)$ \\
\hline Hypotension & $3(1.0)$ & $8(1.3)$ & $34(1.4)$ & $1(0.3)$ & $46(1.3)$ \\
\hline Hypertension & & $8(1.3)$ & $35(1.5)$ & $1(0.3)$ & $44(1.2)$ \\
\hline Hot flushes & & $10(1.7)$ & $30(1.3)$ & $2(0.6)$ & $42(1.2)$ \\
\hline Flushing & $1(0.3)$ & $15(2.5)$ & $24(1.0)$ & & $40(1.1)$ \\
\hline Infections and infestations & $23(7.5)$ & $32(5.3)$ & $117(4.9)$ & $10(3.0)$ & $182(5.0)$ \\
\hline Cystitis & & $6(1.0)$ & $18(0.8)$ & $2(0.6)$ & $26(0.7)$ \\
\hline Folliculitis & $2(0.6)$ & $3(0.5)$ & $12(0.5)$ & & $17(0.5)$ \\
\hline Conjunctivitis & $1(0.3)$ & $3(0.5)$ & $9(0.4)$ & & $13(0.4)$ \\
\hline Influenza & & $1(0.2)$ & $12(0.5)$ & & $13(0.4)$ \\
\hline Hepatobiliary disorders & $27(8.8)$ & $15(2.5)$ & $52(2.2)$ & $40(12.1)$ & $172(4.8)$ \\
\hline Hypertransaminasemia & $13(4.2)$ & $15(2.5)$ & $56(2.4)$ & $30(9.1)$ & $114(3.2)$ \\
\hline Hyperbilirubinemia & $16(5.2)$ & $3(0.5)$ & $10(0.4)$ & $13(3.9)$ & $42(1.2)$ \\
\hline Hepatotoxicity & $8(2.6)$ & & $2(0.1)$ & $7(2.1)$ & $17(0.5)$ \\
\hline Jaundice & $2(0.6)$ & & $1(0.0)$ & $1(0.3)$ & $4(0.1)$ \\
\hline Metabolism and nutrition disorders & $15(4.9)$ & $19(3.1)$ & $47(2.0)$ & $8(2.4)$ & $89(2.5)$ \\
\hline Appetite decreased & $9(2.9)$ & $7(1.2)$ & $17(0.7)$ & $5(1.5)$ & $38(1.1)$ \\
\hline Hypercalcemia & & $3(0.5)$ & $4(0.2)$ & $1(0.3)$ & $8(0.2)$ \\
\hline Hyperglycemia & & $1(0.2)$ & $5(0.2)$ & & $6(0.2)$ \\
\hline Electrolyte imbalance & $1(0.3)$ & $1(0.2)$ & $2(0.1)$ & & $4(0.1)$ \\
\hline $\begin{array}{l}\text { Injury, poisoning, and procedural complica- } \\
\text { tions }\end{array}$ & $4(1.3)$ & $15(2.5)$ & $63(2.7)$ & $3(0.9)$ & $85(2.4)$ \\
\hline Infusion site reaction & & $7(1.2)$ & $51(2.2)$ & $1(0.3)$ & $59(1.6)$ \\
\hline Off-label use & & $2(0.3)$ & $5(0.2)$ & & $7(0.2)$ \\
\hline Toxicity to various agents & & $4(0.7)$ & $3(0.1)$ & & $7(0.2)$ \\
\hline Immune system disorders & & $11(1.8)$ & $40(1.7)$ & $4(1.2)$ & $55(1.5)$ \\
\hline Hypersensitivity & & $9(1.5)$ & $31(1.3)$ & $3(0.9)$ & $43(1.2)$ \\
\hline Anaphylactic shock & & $1(0.2)$ & $5(0.2)$ & & $6(0.2)$ \\
\hline Anaphylactic reaction & & & $3(0.1)$ & & $3(0.1)$ \\
\hline $\begin{array}{l}\text { Neoplasm benign, malignant, and unspecified } \\
\text { (incl. cyst and polyps) }\end{array}$ & $2(0.6)$ & $6(1.0)$ & $7(0.3)$ & $3(0.9)$ & $53(1.5)$ \\
\hline Neoplasm progression & $1(0.3)$ & $18(3.0)$ & $15(0.6)$ & $13(3.9)$ & $47(1.3)$ \\
\hline Metastases to lymph nodes & & $1(0.2)$ & $2(0.1)$ & & $3(0.1)$ \\
\hline Psychiatric disorders & $1(0.3)$ & $7(1.2)$ & $38(1.6)$ & $1(0.3)$ & $47(1.3)$ \\
\hline Insomnia & & $5(0.8)$ & $14(0.6)$ & & $19(0.5)$ \\
\hline Confusional state & $1(0.3)$ & & $5(0.2)$ & & $6(0.2)$ \\
\hline Depression & & $1(0.2)$ & $4(0.2)$ & & $5(0.1)$ \\
\hline Agitation & & & $4(0.2)$ & & $4(0.1)$ \\
\hline Eye disorders & $3(1.0)$ & $8(1.3)$ & $30(1.3)$ & $3(0.9)$ & $44(1.2)$ \\
\hline Xerophthalmia & & $2(0.3)$ & $6(0.3)$ & & $8(0.2)$ \\
\hline Lacrimation increased & & $1(0.2)$ & $5(0.2)$ & $1(0.3)$ & $7(0.2)$ \\
\hline Visual impairment & & $3(0.5)$ & $4(0.2)$ & & $7(0.2)$ \\
\hline Ocular hyperemia & & $1(0.2)$ & $3(0.1)$ & & $4(0.1)$ \\
\hline Renal and urinary disorders & $5(1.6)$ & $5(0.8)$ & $19(0.8)$ & $6(1.8)$ & $35(1.0)$ \\
\hline Dysuria & & $2(0.3)$ & $7(0.3)$ & $3(0.9)$ & $12(0.3)$ \\
\hline Renal failure & $1(0.3)$ & $1(0.2)$ & $2(0.1)$ & & $4(0.1)$ \\
\hline Pollakiuria & & $1(0.2)$ & $2(0.1)$ & & $3(0.1)$ \\
\hline Ear and labyrinth disorders & $2(0.6)$ & $3(0.5)$ & $20(0.8)$ & & $25(0.7)$ \\
\hline
\end{tabular}


Table 2 (continued)

\begin{tabular}{|c|c|c|c|c|c|}
\hline Adverse drug reaction, $n(\%)^{\mathrm{a}}$ & Lapatinib $(n=308)$ & Pertuzumab $(n=604)$ & $\begin{array}{l}\text { Trastuzumab } \\
(n=2367)\end{array}$ & TDM-1 $(n=330)$ & Total $(n=3609)$ \\
\hline Vertigo & $2(0.6)$ & $3(0.5)$ & $15(0.6)$ & & $20(0.6)$ \\
\hline Reproductive system and breast disorders & $1(0.3)$ & $2(0.3)$ & $7(0.3)$ & $1(0.3)$ & $11(0.3)$ \\
\hline Breast pain & & $1(0.2)$ & $1(0.0)$ & & $2(0.1)$ \\
\hline
\end{tabular}

TDM-1 trastuzumab emtansine

${ }^{a}$ Only the most reported adverse drug reactions by Preferred Term were described

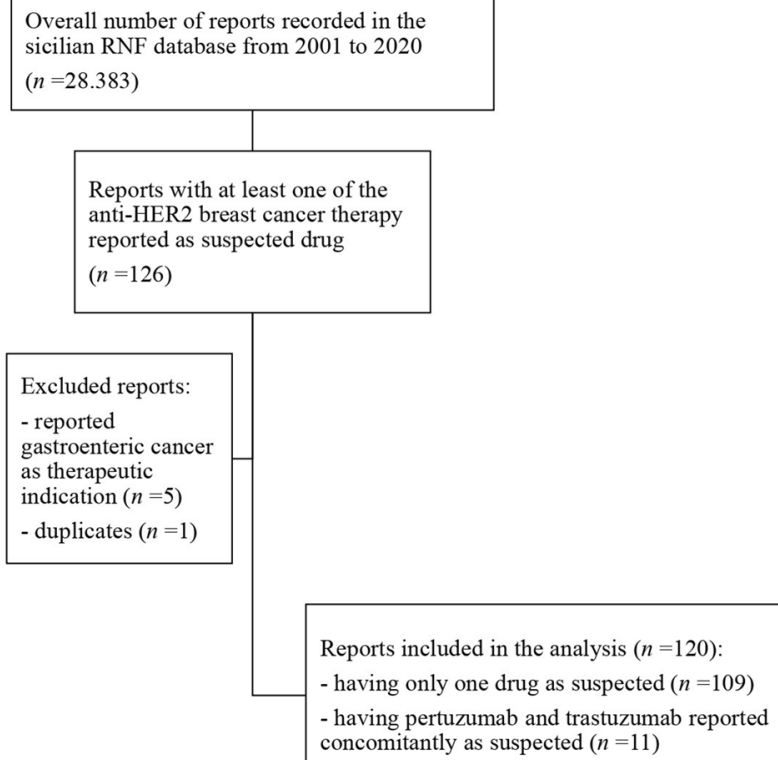

Fig. 2 Flowchart of Sicilian adverse drug reaction (ADR) report selection process. RNF Rete Nazionale di Farmacovigilanza, HER2 human epidermal growth factor receptor type 2

Concerning ADRs, data were expected and confirmed what was reported in the SPCs. This analysis supported the hypothesis that anti-HER 2 therapy is potentially related to the onset of gastrointestinal disorders mainly associated with diarrhea as shown in several studies with TDM-1, pertuzumab, and the combination of lapatinib and capecitabine $[38,39]$. Lapatinib-induced diarrhea may be related to excessive chloride secretion and reduced sodium absorption. The estimated glomerular filtration rate (EGFR), the target of lapatinib, is a negative regulator of chloride secretion and it reduces the secretion of chlorides in intestinal epithelial cells through a mechanism involving protein kinase $\mathrm{C}$ and phosphatidylinositol 3-kinase. For this reason, the EGFR inhibitors can increase chloride secretion by blocking this cycle and consequently induce the discharge of diarrhea, representing a dose-limiting toxicity, particularly when coadministered with capecitabine [40, 41]. Moreover, a higher number of general disorders, especially concerning asthenia, were reported, as also observed in other literature data [35]. Few cases involved pertuzumab-related vascular disorders, mainly hypertension, as shown in another study [42]. In relation to skin disorders, the onset of PPE syndrome with lapatinib was observed [38, 43]. Lapatinib is associated with a higher risk of PPE syndrome, probably related to the use of lapatinib in association with capecitabine; the metabolism of capecitabine occurs via the enzyme thymidine phosphorylase, which is widely expressed in the palms and is responsible of the massive production of 5-fluorouracil in this area with the consequent onset of PPE [44, 45]. Several published studies have reported a higher prevalence of thrombocytopenia during treatment with TDM-1 [46, 47]. The onset of thrombocytopenia could be explained by the use of TDM-1, which inhibits the megakaryocyte differentiation from hematopoietic stem cells and, consequently, the reduced production of platelets [48]. An association between the use of trastuzumab and the onset of cardiac disorders was seen. Unlike the cardiotoxicity induced by anthracyclines, the cardiac damage from anti-HER2 target therapy is not dose-dependent and is reversible upon discontinuation of treatment [15]. Moreover, it is unrelated to histological changes in cardiomyocytes and, consequently, it does not result in structural damage to the myocardium [49]. The mechanism of trastuzumab-induced cardiotoxicity is not well understood; it is proposed to be linked to the inhibition of the neuregulin-1/ErbB (NR-1/ErbB) signaling pathway [50]. Specifically, trastuzumab was associated with the onset of heart failure [51], and both pertuzumab and trastuzumab were associated with the onset of decreased ejection fraction [52]. Considering other serious ADRs, stomatitis occurred in reports having as suspected/concomitant drugs lapatinib + capecitabine [53] and pertuzumab + trastuzumab in association with docetaxel [54]. Oral mucositis (OM) induced by the anti-HER2 therapy is due to nuclear factor- $\mathrm{\kappa B}(\mathrm{NF}-\kappa \mathrm{B})$, considered as the main transcriptional mediator of the $\mathrm{OM}$ process. NF- $\mathrm{kB}$ modulates the transcription of pro-inflammatory cytokines (tumor necrosis factor $\alpha$, TNF- $\alpha$; interleukin-6, IL-6; interleukin-1 $\beta$, IL-1 $\beta$ ) and promotes various drug-resistance mechanisms influencing the development 
Table 3 Characteristics of Sicilian anti-HER2 therapy-related adverse drug reactions reports in the RNF (Rete Nazionale di Farmacovigilanza) database during the period 2006-2020

\begin{tabular}{|c|c|}
\hline Characteristic, $n(\%)$ & Total reports $(n=120)$ \\
\hline \multicolumn{2}{|l|}{ Year of reporting } \\
\hline 2007 & $2(1.7)$ \\
\hline 2008 & $1(0.8)$ \\
\hline 2010 & $4(3.3)$ \\
\hline 2011 & $6(5.0)$ \\
\hline 2012 & $5(4.2)$ \\
\hline 2013 & $4(3.3)$ \\
\hline 2014 & $16(13.3)$ \\
\hline 2015 & $34(28.3)$ \\
\hline 2016 & $14(11.7)$ \\
\hline 2017 & $13(10.8)$ \\
\hline 2018 & $5(4.2)$ \\
\hline 2019 & $13(10.8)$ \\
\hline 2020 & $3(2.5)$ \\
\hline \multicolumn{2}{|l|}{ Gender } \\
\hline Female & $118(98.3)$ \\
\hline Male & $1(0.8)$ \\
\hline Missing & $1(0.8)$ \\
\hline Median age (Q1-Q3), years & $54(49-64.3)$ \\
\hline \multicolumn{2}{|l|}{ Seriousness } \\
\hline Serious & $40(33.3)$ \\
\hline Not serious & $75(62.5)$ \\
\hline Not available & $5(4.2)$ \\
\hline \multicolumn{2}{|l|}{ Type of seriousness } \\
\hline Other medically important conditions & $17(14.2)$ \\
\hline $\begin{array}{l}\text { Hospitalization/prolongation of a pre-existing } \\
\text { hospitalization }\end{array}$ & $14(11.7)$ \\
\hline Life-threatening event & $8(6.7)$ \\
\hline \multicolumn{2}{|l|}{ Outcome } \\
\hline Fully recovered & $46(38.3)$ \\
\hline Improved & $24(20.0)$ \\
\hline Not yet recovered & $15(12.5)$ \\
\hline Recovered with sequelae & $2(1.7)$ \\
\hline Unknown & $33(27.5)$ \\
\hline \multicolumn{2}{|l|}{ Reporter } \\
\hline Physician & $79(65.8)$ \\
\hline Other healthcare professional & $24(20.0)$ \\
\hline Pharmacist & $16(13.3)$ \\
\hline Patient/citizen & $1(0.8)$ \\
\hline \multicolumn{2}{|l|}{ Therapeutic indication } \\
\hline HER $2+$ breast cancer NOS & $64(53.3)$ \\
\hline Metastatic breast cancer & $37(30.8)$ \\
\hline Stage III breast cancer & $3(2.5)$ \\
\hline Stage II breast cancer & $2(1.7)$ \\
\hline Recurrent breast cancer & $2(1.7)$ \\
\hline Breast cancer in situ & $1(0.8)$ \\
\hline Stage I breast cancer & $1(0.8)$ \\
\hline Not defined & $10(8.3)$ \\
\hline
\end{tabular}

Q1 quartile 1, Q3 quartile 3, HER2 human epidermal growth factor receptor type 2, NOS not otherwise specified of $\mathrm{OM}$ and the progression of cancer [53]. Moreover, the present study highlighted serious infusion-related reactions characterized by hypersensitivity and related to pertuzumab and trastuzumab; the use of monoclonal antibodies causes a potential immunogenicity [55]. According to the BC Cancer Agency (BCCA) drug assessment report, infusion-related reactions, including symptoms of asthenia, chills, fatigue, and hypersensitivity, have been observed in from $13.0 \%$ to $40.0 \%$ of patients treated with pertuzumab or trastuzumab $[56,57]$.

The case-by-case assessment of serious Sicilian ADR reports showed that the median TTO was 37 (6-97) days. The median TTO of trastuzumab-related cardiac ADRs was 103 (70.3-259.8) days corresponding to 3.7 (2.5-9.3) months; this was slightly lower than it was observed in a recent study describing a median TTO of cardiac events of 6.6 (3.4-11.7) months [58]. Considering the causality assessment, the majority of ADRs were possible and probable.

\subsection{Strengths and Limitations}

This is the first study aimed as an overview of ADR reports related to treatment approved for HER2-positive breast cancer based on the SRS database. The spontaneous reporting of ADRs is one of the most commonly used methods of post-marketing surveillance, especially for drugs with recent approval [59-61]. Additionally, it is an important source of research into events not occurring in the pre-marketing clinical trial when the drug is administered to a relatively small number of selected patients and in controlled conditions. Nevertheless, SRS has some limitations; first, reports from patients and physicians are voluntary, thus they can result in being under-reported and inject heterogeneity into data; second, comorbidities, detailed treatment information, laboratory exam values, and diagnostic tests are not always available [62]. Moreover, the lack of data about the total number of drug-exposed patients (denominator) does not allow establishment of any meaningful conclusion around headto-head comparison and about the incidence of anti-HER2 therapy-related ADRs [63]. Another important limitation of the present study lies in the fact that a detailed description of ADRs is available only for Sicilian data reported into the Italian SRS database. Indeed, the analysis of Italian data coming from the RAM system is made only in an aggregated form: the RAM system does not allow selection of each single report on the basis of the therapeutic indication only and the use of these drugs for other therapeutic indications cannot be excluded. Furthermore, the analysis of ADRs can potentially be influenced by other antineoplastic drugs used in the same therapeutic regimen or immediately prior to initiation of anti-HER2 therapy. The descriptive analysis only suggests a potential relationship that could be further 
Table 4 Descriptions of adverse drug reactions associated with HER2-positive breast cancer treatment and reported into the Sicilian RNF (Rete Nazionale di Farmacovigilanza) database

\begin{tabular}{|c|c|c|c|c|c|c|}
\hline Adverse drug reaction, $n(\%)^{\mathrm{a}}$ & Lapatinib $(n=27)$ & Pertuzumab $(n=5)$ & $\begin{array}{l}\text { Trastu- } \\
\text { zumab ( } n \\
=59)\end{array}$ & TDM-1 $(n=18)$ & $\begin{array}{l}\text { Pertuzumab/trastu- } \\
\text { zumab }(n=11)\end{array}$ & Total $(n=120)$ \\
\hline $\begin{array}{l}\text { General disorders and administration } \\
\text { site conditions }\end{array}$ & $3(11.1)$ & $3(60.0)$ & $23(39.0)$ & $3(16.7)$ & $4(36.4)$ & $36(30.0)$ \\
\hline Asthenia & $1(3.7)$ & $1(20.0)$ & $2(3.4)$ & $3(16.7)$ & $1(9.1)$ & $8(6.7)$ \\
\hline Chills & & & $6(10.2)$ & & & $6(5.0)$ \\
\hline Chest pain & & $1(20.0)$ & $4(6.8)$ & & & $5(4.2)$ \\
\hline Injection site reaction & & & $4(6.8)$ & & & $4(3.3)$ \\
\hline Gastrointestinal disorders & $14(51.9)$ & $2(40.0)$ & 7 (11.9) & $1(5.6)$ & $4(36.4)$ & $28(23.3)$ \\
\hline Diarrhea & $11(40.7)$ & $1(20.0)$ & $2(3.4)$ & & $3(27.3)$ & $17(14.2)$ \\
\hline Vomiting & $4(14.8)$ & & $3(5.1)$ & & $2(18.2)$ & $9(7.5)$ \\
\hline Nausea & $4(14.8)$ & & $2(3.4)$ & $1(5.6)$ & $1(9.1)$ & $8(6.7)$ \\
\hline Abdominal pain & $1(3.7)$ & $2(40.0)$ & $2(3.4)$ & & & $5(4.2)$ \\
\hline Cardiac disorders & & $1(20.0)$ & $14(23.7)$ & & $3(27.3)$ & $18(15.0)$ \\
\hline Cardiac failure & & & $9(15.3)$ & & & $9(7.5)$ \\
\hline Skin and subcutaneous tissue disorders & $10(37.0)$ & & $4(6.8)$ & $1(5.6)$ & $2(18.2)$ & $17(14.2)$ \\
\hline Rash & $4(14.8)$ & & $4(6.8)$ & & $1(9.1)$ & $9(7.5)$ \\
\hline $\begin{array}{l}\text { Palmar-plantar erythrodysesthesia } \\
\text { syndrome }\end{array}$ & $4(14.8)$ & & & & & $4(3.3)$ \\
\hline Pruritus & $2(7.4)$ & $1(20.0)$ & & & & $3(2.5)$ \\
\hline Blood and lymphatic system disorders & $2(7.4)$ & & & $9(50.0)$ & $3(27.3)$ & $14(11.7)$ \\
\hline Thrombocytopenia & & & & $9(50.0)$ & $2(18.2)$ & $11(9.2)$ \\
\hline Neutropenia & $1(3.7)$ & & & & $2(18.2)$ & $3(2.5)$ \\
\hline Investigations & & $1(20.0)$ & $10(16.9)$ & & $2(18.2)$ & $13(10.8)$ \\
\hline Ejection fraction decreased & & & $7(11.9)$ & & $1(9.1)$ & $8(6.7)$ \\
\hline $\begin{array}{l}\text { Respiratory, thoracic and mediastinal } \\
\text { disorders }\end{array}$ & & $1(20.0)$ & $9(15.3)$ & $2(11.1)$ & & $12(10.0)$ \\
\hline Dyspnea & & & $6(10.2)$ & & & $6(5.0)$ \\
\hline Epistaxis & & & & $2(11.1)$ & & $2(1.7)$ \\
\hline Vascular disorders & $1(3.7)$ & $5(100)$ & $3(5.1)$ & $1(5.6)$ & $1(9.1)$ & $11(9.2)$ \\
\hline Hypotension & $1(3.7)$ & $1(20.0)$ & $1(1.7)$ & & & $3(2.5)$ \\
\hline Nervous system disorders & & & 7 (11.9) & $1(5.6)$ & & $10(8.3)$ \\
\hline Tremor & & $1(20.0)$ & $5(8.5)$ & $1(5.6)$ & & $7(5.8)$ \\
\hline Headache & & & & & & $4(3.3)$ \\
\hline Hepatobiliary disorders & $2(7.4)$ & $1(20.0)$ & $1(1.7)$ & $4(22.2)$ & $2(18.2)$ & $8(6.7)$ \\
\hline Hypertransaminasemia & $1(3.7)$ & $1(20.0)$ & & & $1(9.1)$ & $6(5.0)$ \\
\hline Metabolism and nutrition disorders & $3(11.1)$ & & $1(1.7)$ & $2(11.1)$ & $1(9.1)$ & $7(5.8)$ \\
\hline Appetite decreased & $2(7.4)$ & & & & & $4(3.3)$ \\
\hline $\begin{array}{l}\text { Musculoskeletal and connective tissue } \\
\text { disorders }\end{array}$ & & & $3(5.1)$ & $1(5.6)$ & $1(9.1)$ & $5(4.2)$ \\
\hline Muscle spasms & & & $1(1.7)$ & & $1(9.1)$ & $2(1.7)$ \\
\hline Infections and infestations & $2(7.4)$ & & $3(5.1)$ & & & $5(4.2)$ \\
\hline $\begin{array}{l}\text { Injury, poisoning and procedural } \\
\text { complications }\end{array}$ & & & $4(6.8)$ & & & $4(3.3)$ \\
\hline Immune system disorders & & $1(20.0)$ & $3(5.1)$ & & & $4(3.3)$ \\
\hline Hypersensitivity & & & $3(5.1)$ & & & $3(2.5)$ \\
\hline Renal and urinary disorders & $2(7.4)$ & $1(20.0)$ & & & & $3(2.5)$ \\
\hline Renal failure & $1(3.7)$ & $1(20.0)$ & & & & $2(1.7)$ \\
\hline $\begin{array}{l}\text { Neoplasm benign, malignant, and } \\
\text { unspecified (incl. cyst and polyps) }\end{array}$ & & & $1(1.7)$ & $1(5.6)$ & & $2(1.7)$ \\
\hline $\begin{array}{l}\text { Reproductive system and breast } \\
\text { disorders }\end{array}$ & & & $1(1.7)$ & & & $1(0.8)$ \\
\hline
\end{tabular}

TDM-1 trastuzumab emtansine

${ }^{a}$ Only the most reported adverse drug reactions by Preferred Term were described 


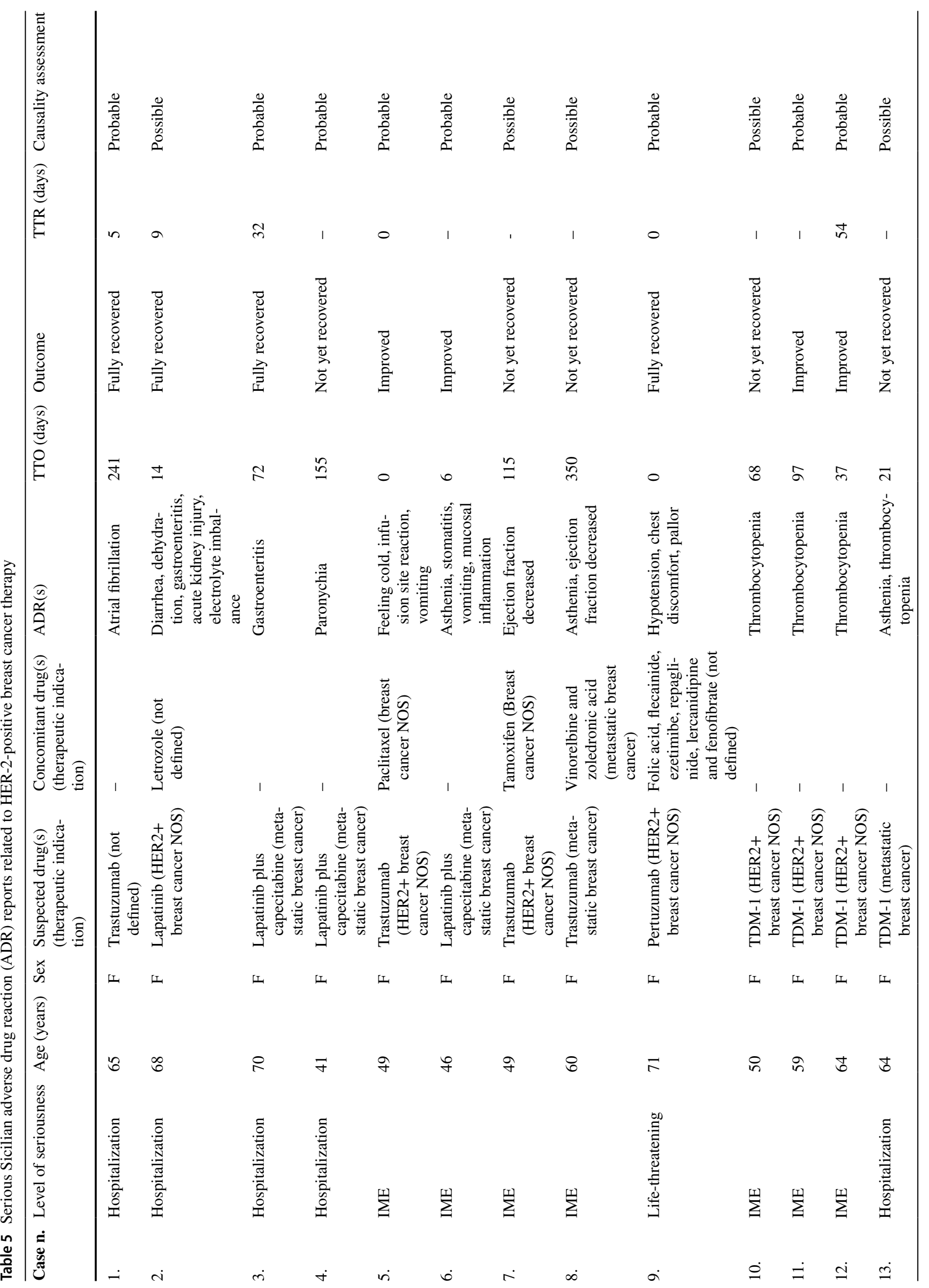




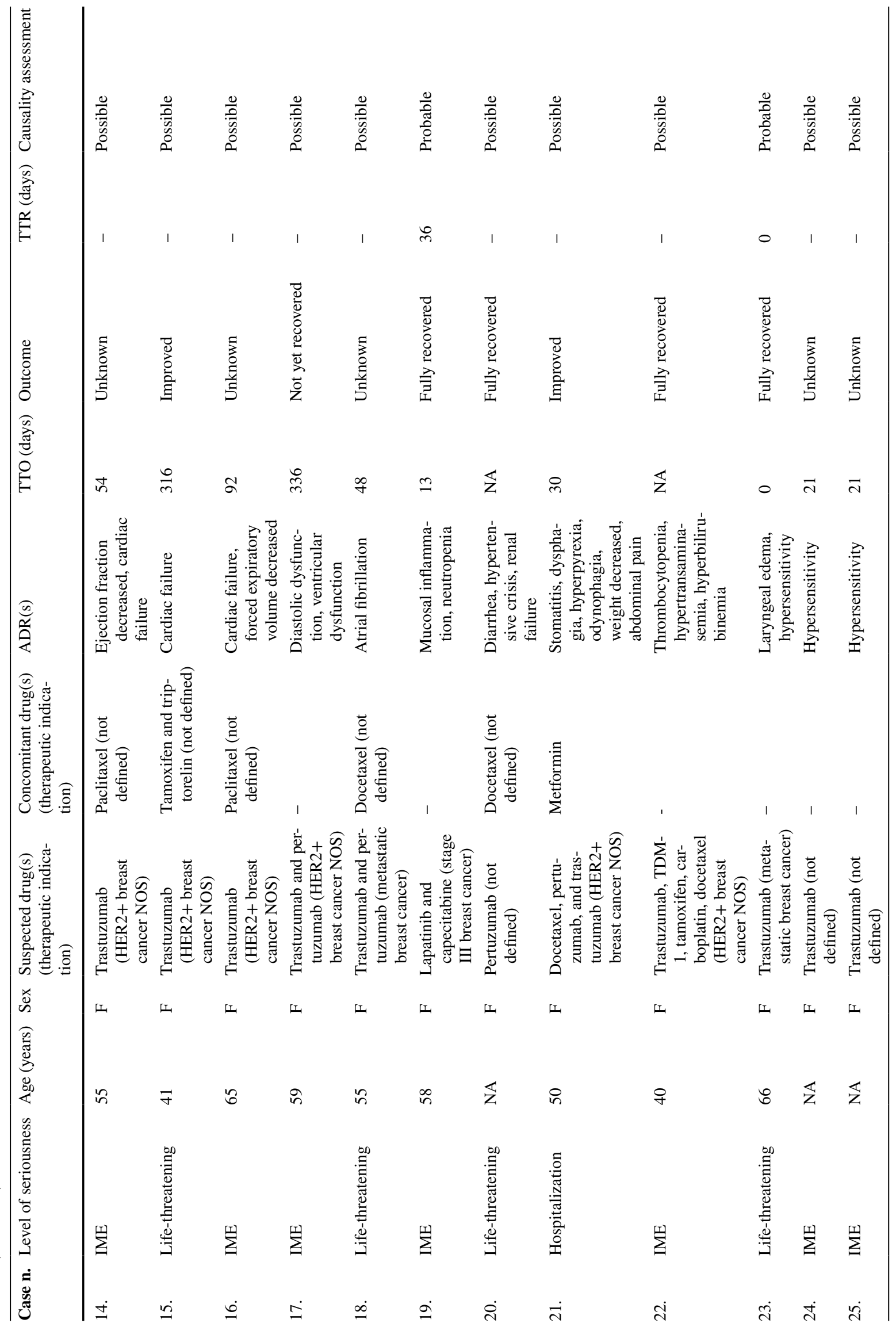




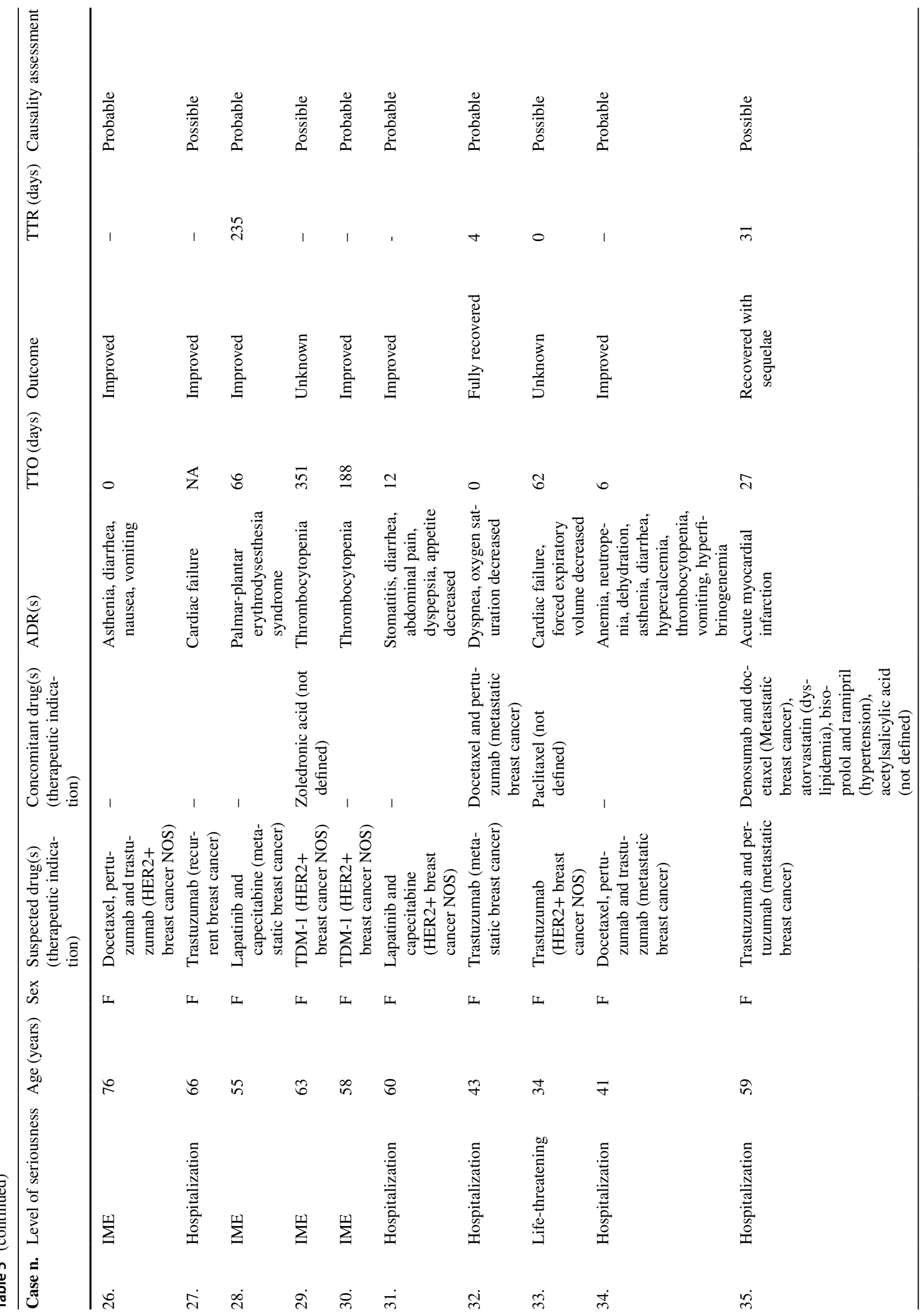




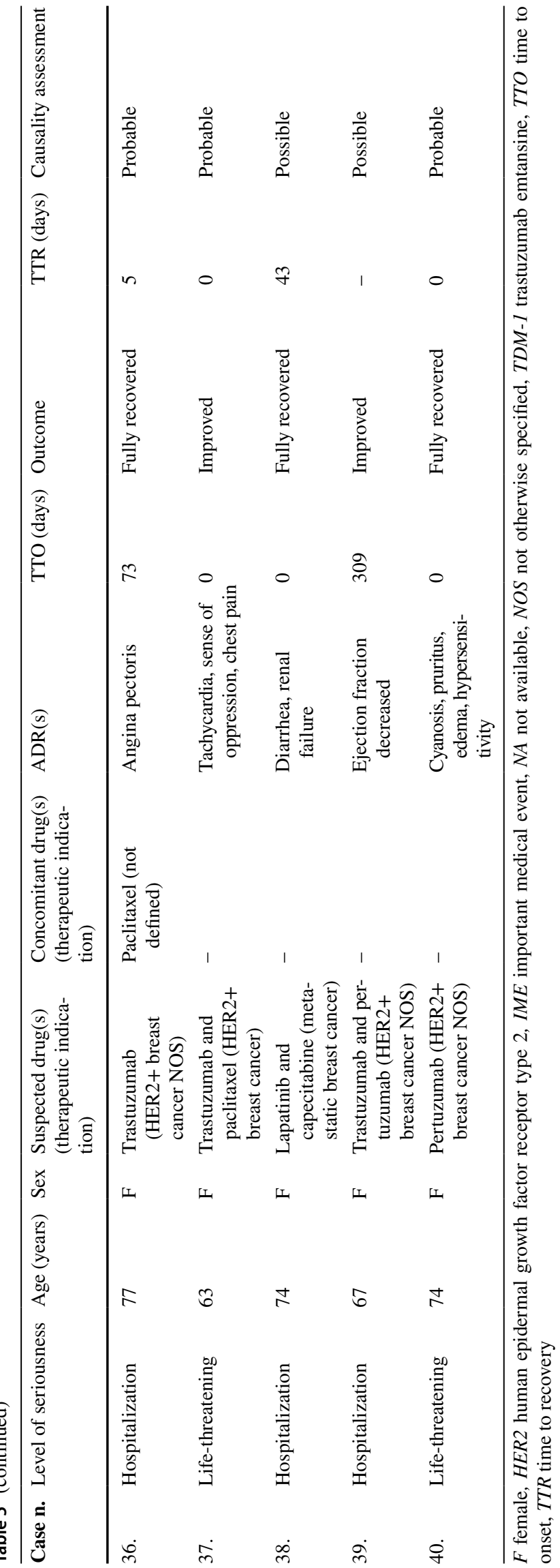

investigated to generate a real signal $[59,64]$. Despite these limitations, it is mainly recognized that SRS contributes to the characterization of safety profiles, which is particularly important for preventing some ADRs related to the use of anti-HER 2 therapy in the treatment of breast cancer.

\section{Conclusion}

The importance of the SRS database for the identification of ADRs induced by anti-HER2 therapy is shown in the present study. The obtained data are mainly consistent with results in the literature. However, more attention should be paid to the occurrence of serious ADRs including heart failure, PPE syndrome, thrombocytopenia, and infusion-related reactions. Moreover, breast cancer is a heterogeneous disease and sometimes presents a very aggressive behavior causing clinically relevant symptoms and limitations to quality of life. This is particularly relevant in older patients or those with multiple comorbidities, underlining the importance of preventing some relevant ADRs, related to the use of antiHER2 therapy, to improve patients' compliance. Further analyses are essential to better describe the safety profile of these target therapies and to develop proactive management strategies. The collaboration between oncologists and pharmacologists plays an essential role in early identification of ADRs, informing patients and improving their awareness of needing to report any new symptoms or worsening of a pre-existing condition as soon as possible during anti-HER2 therapy.

Supplementary Information The online version contains supplementary material available at https://doi.org/10.1007/s40801-021-00278-z.

\section{Declarations}

Funding No sources of funding were used to prepare this article.

Conflict of interest Maria Antonietta Barbieri, Emanuela Elisa Sorbara, Giuseppe Cicala, Vincenza Santoro, Paola Maria Cutroneo, Tindara Franchina, and Edoardo Spina have no conflicts of interest that are relevant to the content of this article. The research was conducted in the absence of any commercial or financial relationships that could be construed as a potential conflict of interest.

Ethics approval The study was approved by the Ethics Committee of Messina (protocol number 13/2021; approved on 26 January 2021).

Consent to participate Not applicable.

Consent for publication Not applicable.

Availability of data and material The datasets generated for this study will not be made publicly available. National dataset in aggregated form is available online, while the access to the regional in single, non-aggregated dataset requires the approval of the Italian Medicine Agency. 
Author contributions All authors listed have sufficiently contributed to the entire content of the manuscript and have given their consent for publication. Project coordination: Edoardo Spina Acquisition of data: Paola Maria Cutroneo and Edoardo Spina. Analysis and interpretation of data: Maria Antonietta Barbieri, Emanuela Elisa Sorbara, Giuseppe Cicala, and Vincenza Santoro. Clinical evaluation of data: Tindara Franchina and Edoardo Spina. Wrote the paper: Maria Antonietta Barbieri, Emanuela Elisa Sorbara, and Tindara Franchina. Critical revision: Paola Maria Cutroneo, Tindara Franchina, and Edoardo Spina. Final approval of the version to be published: Maria Antonietta Barbieri, Emanuela Elisa Sorbara, Giuseppe Cicala, Vincenza Santoro, Paola Maria Cutroneo, Tindara Franchina, and Edoardo Spina.

Open Access This article is licensed under a Creative Commons Attribution-NonCommercial 4.0 International License, which permits any non-commercial use, sharing, adaptation, distribution and reproduction in any medium or format, as long as you give appropriate credit to the original author(s) and the source, provide a link to the Creative Commons licence, and indicate if changes were made. The images or other third party material in this article are included in the article's Creative Commons licence, unless indicated otherwise in a credit line to the material. If material is not included in the article's Creative Commons licence and your intended use is not permitted by statutory regulation or exceeds the permitted use, you will need to obtain permission directly from the copyright holder. To view a copy of this licence, visit http://creativecommons.org/licenses/by-nc/4.0/.

\section{References}

1. Sung H, Ferlay J, Siegel RL, Laversanne M, Soerjomataram I, Jemal A, et al. Global cancer statistics 2020: GLOBOCAN estimates of incidence and mortality worldwide for 36 cancers in 185 countries. CA Cancer J Clin. 2021;71:209-49.

2. Waks AG, Winer EP. Breast cancer treatment: a review. JAMA J Am Med Assoc. 2019;321:288-300.

3. Stefania G, Giuseppe A, Paolo A, Sergio B, Vanna Chiarion S, Alessandro $\mathrm{C}$ et al. I numeri del cancro in Italia. In: Rep AIOMAIRTUM. 2020; 1-232.

4. Wang J, Xu B. Targeted therapeutic options and future perspectives for her2-positive breast cancer. Signal Transduct Target Ther. 2019;4:34.

5. Slamon DJ, Godolphin W, Jones LA, Holt JA, Wong SG, Keith $\mathrm{DE}$, et al. Studies of the HER-2/neu proto-oncogene in human breast and ovarian cancer. Science. 1989;244:707-12.

6. Ferguson KM. Structure-based view of epidermal growth factor receptor regulation. Annu Rev Biophys. 2008;37:353-73.

7. Iqbal N, Iqbal N. Human epidermal growth factor receptor 2 (HER2) in cancers: overexpression and therapeutic implications. Mol Biol Int. 2014;852748:1-9.

8. Hanahan D, Weinberg RA. Hallmarks of cancer: the next generation. Cell. 2011;144:646-74.

9. Choong GM, Cullen GD, O'Sullivan CC. Evolving standards of care and new challenges in the management of HER2-positive breast cancer. CA Cancer J Clin. 2020;70:355-74.

10. Dormann C. Metastatic human epidermal growth factor receptor 2-positive breast cancer: current treatment standards and future perspectives. Breast Care. 2020;15:570-8.

11. Swain SM, Miles D, Kim SB, Im YH, Im SA, Semiglazov V, et al. Pertuzumab, trastuzumab, and docetaxel for HER2-positive metastatic breast cancer (CLEOPATRA): end-of-study results from a double-blind, randomised, placebo-controlled, phase 3 study. Lancet Oncol. 2020;21:519-30.
12. European Medicines Agency. Kadcyla ${ }^{\circledR}$, summary of product characteristics (internet). 2013. Cited 12 Apr 2021. pp. 1-48. https://www.ema.europa.eu/en/documents/product-information/ kadcyla-epar-product-information_en.pdf. Accessed 15 Nov 2013.

13. European Medicines Agency. Tyverb ${ }^{\circledR}$, summary of product characteristics (internet). 2008. Cited 12 Apr 2021. pp. 1-45. https:// www.ema.europa.eu/en/documents/product-information/tyverbepar-product-information_en.pdf. Accessed 10 June 2008.

14. European Medicines Agency. Nerlynx ${ }^{\circledR}$, summary of product characteristics (internet). 2018. Cited 12 Apr 2021. pp. 1-33. https://www.ema.europa.eu/en/documents/product-information/ nerlynx-epar-product-information_en.pdf. Accessed 31 Aug 2018

15. Jerusalem G, Lancellotti P, Kim SB. HER2+ breast cancer treatment and cardiotoxicity: monitoring and management. Breast Cancer Res Treat. 2019;177:237-50.

16. Eiger D, Franzoi MA, Pondé N, Brandão M, De Angelis C, Schmitt Nogueira M, et al. Cardiotoxicity of trastuzumab given for 12 months compared to shorter treatment periods: a systematic review and meta-analysis of six clinical trials. ESMO Open. 2020;5:e000659.

17. Hurvitz SA, Martin M, Symmans WF, Jung KH, Huang CS, Thompson AM, et al. Neoadjuvant trastuzumab, pertuzumab, and chemotherapy versus trastuzumab emtansine plus pertuzumab in patients with HER2-positive breast cancer (KRISTINE): a randomised, open-label, multicentre, phase 3 trial. Lancet Oncol. 2018;19:115-26.

18. Miles D, Baselga J, Amadori D, Sunpaweravong P, Semiglazov V, Knott A, et al. Treatment of older patients with HER2-positive metastatic breast cancer with pertuzumab, trastuzumab, and docetaxel: Subgroup analyses from a randomized, double-blind, placebo-controlled phase III trial (CLEOPATRA). Breast Cancer Res Treat. 2013;142:89-99.

19. von Minckwitz G, Procter M, de Azambuja E, Zardavas D, Benyunes M, Viale G, et al. Adjuvant pertuzumab and trastuzumab in early HER2-positive breast cancer. N Engl J Med. 2017;377:122-31.

20. Gianni L, Pienkowski T, Im YH, Tseng LM, Liu MC, Lluch A, et al. 5-year analysis of neoadjuvant pertuzumab and trastuzumab in patients with locally advanced, inflammatory, or early-stage HER2-positive breast cancer (NeoSphere): a multicentre, openlabel, phase 2 randomised trial. Lancet Oncol. 2016;17:791-800.

21. Schneeweiss A, Chia S, Hickish T, Harvey V, Eniu A, Hegg R, et al. Pertuzumab plus trastuzumab in combination with standard neoadjuvant anthracycline-containing and anthracyclinefree chemotherapy regimens in patients with HER2-positive early breast cancer: a randomized phase II cardiac safety study (TRYPHAENA). Ann Oncol (Internet; Elsevier Masson SAS). 2013;24:2278-84. https://doi.org/10.1093/annonc/mdt182.

22. Hackshaw MD, Danysh HE, Singh J, Ritchey ME, Ladner A, Taitt $\mathrm{C}$, et al. Incidence of pneumonitis/interstitial lung disease induced by HER2-targeting therapy for HER2-positive metastatic breast cancer. Breast Cancer Res Treat. 2020;183:23-9.

23. Paech F, Bouitbir J, Krähenbühl S. Hepatocellular toxicity associated with tyrosine kinase inhibitors: mitochondrial damage and inhibition of glycolysis. Front Pharmacol. 2017;8:1-13.

24. Miles J, White Y. Neratinib for the treatment of early-stage HER2positive breast cancer. J Adv Pr Oncol. 2018;9:750-4.

25. Li Y, Gong C, Lu Q, Zhou Z, Luo T, Li W, et al. Real-world data of triplet combination of trastuzumab, lapatinib, and chemotherapy in HER2-positive metastatic breast cancer: a multicenter retrospective study. Front Oncol. 2020;10:1-10.

26. European Medicines Agency. Guideline on good pharmacovigilance practices (GVP) Annex I - definitions (rev 4) (internet). Heads Medicine Agencies. 2017. https://www.ema.europa.eu/en/ documents/scientific-guideline/guideline-good-pharmacovigilan ce-practices-annex-i-definitions-rev-4_en.pdf 
27. Naranjo CA, Busto U, Sellers EM, Sandor P, Ruiz I, Roberts EA, et al. A method for estimating the probability of adverse drug reactions. Clin Pharmacol Ther. 1981;30:239-45.

28. European Medicines Agency. Human medicines (internet). 2021. http://www.ema.europa.eu/ema/index.jsp?curl=pages/medicines/ landing/epar_search.jsp\&mid=WC0b01ac058001d124

29. Miao H, Verkooijen HM, Chia KS, Bouchardy C, Pukkala E, Larønningen $S$, et al. Incidence and outcome of male breast cancer: an international population-based study. J Clin Oncol. 2011;29:4381-6.

30. Wang F, Shu X, Meszoely I, Pal T, Mayer IA, Yu Z, et al. Overall mortality after diagnosis of breast cancer in men vs women. JAMA Oncol. 2019;5:1589-96.

31. De Lorenzi F, Loschi P, Bagnardi V, Rotmensz N, Hubner G, Mazzarol G, et al. Oncoplastic breast-conserving surgery for tumors larger than 2 centimeters: is it oncologically safe? A matchedcohort analysis. Ann Surg Oncol. 2016;23:1852-9.

32. Barcelos FC, De Matos GC, Da Silva MJS, Da Silva FAB, Da Costa LE. Suspected adverse drug reactions related to breast cancer chemotherapy: disproportionality analysis of the Brazilian spontaneous reporting system. Front Pharmacol. 2019;10:1-6.

33. DeSantis C, Ma J, Bryan L, Jemal A. Breast cancer statistics, 2013. CA Cancer J Clin. 2014;64:52-62.

34. Blackwell KL, Burstein HJ, Storniolo AM, Rugo HS, Sledge G, Aktan G, et al. Overall survival benefit with lapatinib in combination with trastuzumab for patients with human epidermal growth factor receptor 2-positive metastatic breast cancer: final results from the EGF104900 study. J Clin Oncol. 2012;30:2585-92.

35. Scavone C, Sportiello L, Sullo MG, Ferrajolo C, Ruggiero R, Sessa M, et al. Safety profile of anticancer and immune-modulating biotech drugs used in a real world setting in Campania Region (Italy): BIO-Cam observational study. Front Pharmacol. 2017;8:607.

36. European Medicines Agency. Herceptin ${ }^{\circledR}$, summary of product characteristics (internet). 2000. pp. 1-91. https://www.ema. europa.eu/en/documents/product-information/herceptin-eparproduct-information_en.pdf. Accessed 12 Apr 2021.

37. Agenzia Italiana del Farmaco. The Medicines Utilisation Monitoring Centre. National Report on Medicines Use in Italy. Year 2015 (internet). 2016. http://www.agenziafarmaco.gov.it/sites/default/ files/Rapporto_OsMed_2015_AIFA-acc.pdf. Accessed 30 Mar 2021.

38. Diéras V, Miles D, Verma S, Pegram M, Welslau M, Baselga J, et al. Trastuzumab emtansine versus capecitabine plus lapatinib in patients with previously treated HER2-positive advanced breast cancer (EMILIA): a descriptive analysis of final overall survival results from a randomised, open-label, phase 3 trial. Lancet Oncol. 2017;18:732-42.

39. Moisan A, Michielin F, Jacob W, Kronenberg S, Wilson S, Avignon B, et al. Mechanistic investigations of diarrhea toxicity induced by Anti-HER2/3 combination therapy. Mol Cancer Ther. 2018;17:1464-74.

40. Uribe JM, Barrett KIME, Diego S, Gelbmann M, Barrett KE. Epidermal transport growth factor inhibits $\mathrm{Ca} 2+$-dependent in T84 human colonic epithelial cells Cl-. Am J Physiol. 1996;271:C914-22.

41. Dranitsaris G, Lacouture ME. Development of prediction tools for diarrhea and rash in breast cancer patients receiving lapatinib in combination with capecitabine. Breast Cancer Res Treat. 2014; 147:631-8.

42. Wildiers H, Tryfonidis K, Dal Lago L, Vuylsteke P, Curigliano $\mathrm{G}$, Waters S, et al. Pertuzumab and trastuzumab with or without metronomic chemotherapy for older patients with HER2-positive metastatic breast cancer (EORTC 75111-10114): an open-label, randomised, phase 2 trial from the Elderly Task Force/Breast Cancer Group. Lancet Oncol. 2018;19:323-36.
43. Xu BH, Jiang ZF, Chua D, Shao ZM, Luo RC, Wang XJ, et al. Lapatinib plus capecitabine in treating HER2-positive advanced breast cancer: efficacy, safety, and biomarker results from Chinese patients. Chin J Cancer. 2011;30:327-35.

44. Ang FLI, Rowland A, Modi ND, McKinnon RA, Sorich MJ, Hopkins AM. Early adverse events predict survival outcomes in HER2-positive advanced breast cancer patients treated with lapatinib plus capecitabine. J Cancer. 2020;11:3327-33.

45. Abdel-Rahman O, Fouad M. Risk of mucocutaneous toxicities in patients with solid tumors treated with lapatinib: a systematic review and meta-analysis. Curr Med Res Opin. 2015;31:975-86.

46. Thon JN, Devine MT, Begonja AJ, Tibbitts J, Italiano JE. Highcontent live-cell imaging assay used to establish mechanism of trastuzumab emtansine (T-DM1)-mediated inhibition of platelet production. Blood. 2012;120:1975-84.

47. Verma S, Miles D, Gianni L, Krop IE, Welslau M, Baselga J, et al. Trastuzumab emtansine for HER2-positive advanced breast cancer. N Engl J Med. 2012;367:1783-91.

48. Uppal H, Doudement E, Mahapatra K, Darbonne WC, Bumbaca D, Shen BQ, et al. Potential mechanisms for thrombocytopenia development with trastuzumab emtansine (T-DM1). Clin Cancer Res. 2015;21:123-33.

49. Suter TM, Cook-Bruns N, Barton C. Cardiotoxicity associated with trastuzumab (Herceptin) therapy in the treatment of metastatic breast cancer. Breast. 2004;13:173-83.

50. Yu AF, Mukku RB, Verma S, Liu JE, Oeffinger KC, Steingart RM, et al. Cardiac safety of non-anthracycline trastuzumab-based therapy for HER2-positive breast cancer. Breast Cancer Res Treat. 2017;166:241-7.

51. Balduzzi S, Mantarro S, Guarneri V, Tagliabue L, Pistotti V, Moja $\mathrm{L}$, et al. Trastuzumab-containing regimens for metastatic breast cancer. Cochrane Database Syst Rev. 2014;2014:CD006242.

52. Bachelot T, Ciruelos E, Schneeweiss A, Puglisi F, Peretz-Yablonski T, Bondarenko I, et al. Preliminary safety and efficacy of firstline pertuzumab combined with trastuzumab and taxane therapy for HER2-positive locally recurrent or metastatic breast cancer (PERUSE). Ann Oncol. 2019;30:766-73.

53. Pulito C, Cristaudo A, La Porta C, Zapperi S, Blandino G, Morrone A, et al. Oral mucositis: the hidden side of cancer therapy. J Exp Clin Cancer Res. 2020;39:1-15.

54. Basile D, Di Nardo P, Corvaja C, Garattini SK, Pelizzari G, Lisanti C, et al. Mucosal injury during anti-cancer treatment: From pathobiology to bedside. Cancers (Basel). 2019;11:1-22.

55. Gülsen A, Wedi B, Jappe U. Hypersensitivity reactions to biologics (part I): allergy as an important differential diagnosis in complex immune-derived adverse events. Allergo J Int. 2020;29:97-125.

56. BC Cancer Agency. Cancer drug manual, drug name: trastuzumab (internet). 2020. http://www.bccancer.bc.ca/drugdatabase-site/ DrugIndex/Trastuzumab_monograph.pdf. Accessed 30 Mar 2021.

57. BC Cancer Agency. Cancer drug manual, drug name: pertuzumab (internet). 2014. http://www.bccancer.bc.ca/drugdatabase-site/ DrugIndex/Pertuzumab_monograph_1Jan2014.pdf. Accessed 30 Mar 2021.

58. Eiger D, Pondé NF, Agbor-Tarh D, Moreno-Aspitia A, Piccart M, Hilbers FS, et al. Long-term cardiac outcomes of patients with HER2-positive breast cancer treated in the adjuvant lapatinib and/ or trastuzumab Treatment Optimization Trial. Br J Cancer (internet; Springer, US). 2020;122:1453-60. https://doi.org/10.1038/ s41416-020-0786-x.

59. Raschi E, Moretti U, Salvo F, Pariente A, Cosimo Antonazzo I, De Ponti $\mathrm{F}$ et al. Evolving roles of spontaneous reporting systems to assess and monitor drug safety. Pharmacovigilance. 2019.

60. Galatti L, Giustini SE, Sessa A, Polimeni G, Salvo F, Spina E, et al. Neuropsychiatric reactions to drugs: an analysis of 
spontaneous reports from general practitioners in Italy. Pharmacol Res. 2005;51:211-6.

61. Barbieri MA, Cutroneo PM, Baratelli C, Cicala G, Battaglia A, Santoro V, et al. Adverse drug reactions with oral anticoagulants: data from sicilian spontaneous reporting system database. J Clin Pharm Ther. 2021;46:1027-40.

62. Palleria C, Leporini C, Chimirri S, Marrazzo G, Sacchetta S, Bruno L, et al. Limitations and obstacles of the spontaneous adverse drugs reactions reporting: two "challenging" case reports. J Pharmacol Pharmacother. 2013;4:S66-72.
63. Pal SN, Duncombe C, Falzon D, Olsson S. WHO strategy for collecting safety data in public health programmes: complementing spontaneous reporting systems. Drug Saf. 2013;36:75-81.

64. Barbieri MA, Cicala G, Cutroneo PM, Mocciaro E, Sottosanti L, Freni F, et al. Ototoxic adverse drug reactions: a disproportionality analysis using the italian spontaneous reporting database. Front Pharmacol. 2019;10:1161. 